\title{
THE FORCE OF NONVIOLENCE
}

\author{
Antoni Isidor Marí Marí \\ Universitat de Barcelona \\ marimari.antoni.i@gmail.com
}

Reseña de: Butler, Judith. (2020). The Force of Nonviolence. Londres:

Verso.

¿Cómo afirmar una praxis política verdaderamente comprometida con la preservación de la vida y de las condiciones que la hacen posible? ¿Cómo vehicular la fuerza, la agresividad y las pasiones ambivalentes que entran en juego en la política, con un hacer que afirme la igualdad de todas las vidas de ser (potencialmente) Iloradas? Pero, sobre todo, cómo hacerlo en un mundo en el que una persona racializada, víctima de violencia policial, puede y es Ilevada a juicio acusada de la violencia que padece. En un mundo en el que protestas pacíficas en contra de medidas represivas son tachadas y tratadas por la ley y el Estado como violentas; donde miles de refugiados son dejados a morir en el mar Mediterráneo o en las vallas fronterizas de Europa, en condiciones deplorables, mientras esperan asilo. En un mundo donde millones de mujeres, personas trans, queer, gays, lesbianas e identidades disidentes son nombradas como violentas por manifestarse precisamente contra la extrema violencia que padecen día a día. Es desde estas urgencias, desde y para estas vidas, vidas precarizadas, dejadas a morir, que Judith Butler escribe su último texto hasta la fecha.

The Force of Nonviolence (Butler, 2020) es la afirmación de la posición de Judith Butler frente a los debates recientes en torno a la violencia en la izquierda política y académica ${ }^{1}$, así como la situación convulsa que vivimos en la actualidad. En este texto la autora incita una fecunda reflexión a partir y hacia movimientos sociales, como el Me Too en Estados Unidos o Ni Una Menos en Latinoamérica, a la luz del diálogo con autorxs como Foucault, Fanon, Freud, Klein y Benjamin.

Los temas y reflexiones que despliega Butler en esta obra son materiales que ha ido trabajando y exponiendo durante los últimos años. Los diversos capítulos son elaboraciones a partir de los seminarios que ha ido impartiendo en la Universidad de Yale (2016), Glasgow (2018) y Dublín (2019), así como reflexiones a partir de los diálogos Ilevados a cabo en centros como el Centre de Cultura Contemporània de Barcelona, la Universidad de Meiji, Tokyo, o la Universidad de Zúrich. Este texto se escribe pues, no desde una posición teórica o académica, sino desde la voluntad de confundir e integrar su voz con la de los movimientos sociales recientes (algunos de ellos ya mencionados), y dar una respuesta a las encrucijadas que azotan la vida de todxs en la actualidad.

\footnotetext{
${ }^{1}$ Véase Žižek (2008), Agamben (2005), Derrida (1991), Foucault (2004) o Benjamin (1998).
} 
La obra inmediatamente anterior a The Force of Nonviolence, esto es, Frames of War: When is life grievable? (Butler, 2009), concluye con el capítulo "The Claim of Nonviolence" (traducido al catalán como "La reivindicació de la No-violència" (Butler, 2019)). En este, la filósofa invoca un "grito", un Ilamamiento a una posición afirmativa desde la no violencia. Es a partir de este capítulo y de los ya nombrados seminarios, impartidos durante estos últimos años, que Butler coge el relevo y afirma dicha posición, ya no desde un Ilamamiento, sino desde la fuerza que esta contiene.

Así, The Force of Nonviolence se enmarca en la línea que Butler viene trazando con sus publicaciones más recientes, inaugurada con Precarious life: The Power of Mourning and Violence (Butler, 2004), seguida de Frames of War: When is life grievable? y extendida con numerosos artículos y publicaciones, como Violència d'estat, guerra i resistència (Butler, 2010) o Vulnerabilitat, supervivència (Butler, 2008). La autora responde a la urgencia del presente y a las exigencias de su propia obra con una posición afirmativa: una no violencia agresiva y militante, contrapuesta a posiciones individualistas y pasivas; una posición íntimamente comprometida con la igualdad, la preservación de la vida y las condiciones que la hacen posible.

Ya en el inicio Butler traza, a través de citas, un linaje a partir del cual se inspira en la reflexión que sigue: se trata de citas de Mahatma Gandhi, Martin Luther King Jr. y Angela Davis. Asimismo, empieza señalando que el problema principal que se presenta al elaborar una posición no violenta es precisamente definir qué entendemos por violencia y por no violencia. La búsqueda de determinación de un atributo esencial que caracteriza la violencia se vuelve escurridiza, puesto que en muchos casos esta adquiere la forma del golpe (blow) físico, pero no se limita a este campo (pues podemos considerar otros tipos de violencia no-física como la violencia verbal, la violencia institucional, la precariedad...). A su vez, la distinción entre violencia y no violencia está atravesada por una confusión lingüística: el hecho de que una misma práctica pueda ser nombrada como violenta por el estado, y como no violenta por aquellas personas que la ejercen, pone de relieve que la caracterización de un acto como "violento" depende del ser nombrado y del poder que nombra.

En diálogo con Walter Benjamin y su obra Para una crítica de la violencia (1998), de la que hace una potente interpretación a través de otros textos de Benjamin como "La tarea del traductor" (2010) y "Sobre el lenguaje en general y sobre el lenguaje de los humanos" (1998), la filósofa afirma que el monopolio de la violencia por parte del Estado se mantiene a través de la práctica exclusiva de nombrar como violentos ciertos actos, práctica que se sustenta en un campo de fuerza estatal, social y discursivo. Este campo de fuerza opera e insiste en el seno de la vida social, determinando qué vidas merecen ser lloradas y qué vidas son consideradas como ya perdidas de antemano.

A partir del concepto de biopoder foucaultiano, Butler traza y piensa a partir de la noción de "vidas lloradas" (grievability), esto es, cómo una vida, para ser reconocida como tal en el campo de fuerza estatal, debe ser leída como una vida poseedora de un valor incuantificable, una vida que debe ser protegida y (potencialmente) Ilorada si muriera. Es esta capacidad de "ser Ilorada" la que le da a la vida su verdadero estatuto, y es esta capacidad la que el poder estatal regula y niega a ciertas vidas, prohibiendo el marco social, lingüístico, cultural e intersubjetivo de su reconocimiento. En ausencia de este marco, las vidas dejadas a morir son vidas perdidas: como señala 
Butler, "We cannot lose those who cannot be grieved. They are treated as beyond losing, already lost, never living, never having been entitled to life" (2020:122).

En todo el mundo, y especialmente en los Estados Unidos, esta fuerza estatal y social que determina el estatuto de la vida está atravesada por el racismo institucionalizado. Recogiendo el proyecto foucaultiano trazado en seminarios como Naissance de la biopolitique (2004), y ensamblándolo con la noción de "the zone of non-being" trazada por Frantz Fanon, Butler desarrolla el concepto de phantasma racial (racial phantasm). Este phantasma, que Butler articula a partir de la obra de Melanie Klein (y que escribe con ph- para diferenciar y recalcar su carácter psicoanalítico), es la imagen especular que atraviesa todo el tejido social e instaura a las personas racializadas, aquellas que padecen una brutal violencia policial y estatal, como sujetos leídos bajo las categorías de "violentos", potencialmente violentos o incluso como "pura violencia encarnada" (Butler, 2020: 4). Así, el marco de poder policial y estatal se justifica a sí mismo, invirtiendo el sentido de la violencia y estableciendo su poder como legítimo y justo. La simple existencia de las personas racializadas queda leída como "violencia", como aquello de lo que hay que protegerse. Una vez más, las vidas de estas personas son determinadas como "no llorables", como ya perdidas, inexistentes; como nunca llegadas a ser vidas.

Por ello, una posición verdaderamente comprometida con la igualdad debe tener en cuenta este marco, debe hacer inoperativa la distinción entre vidas (potencialmente) Iloradas y vidas "ya perdidas". Y es en la justificación de la violencia como autodefensa que se repite, una vez más, esta distinción: una distinción entre las vidas que merecen ser protegidas mediante la violencia, y unas vidas de las que hay que protegerse, Ilegando incluso a su destrucción; distinción atravesada por la problemática de establecer de antemano un(os) sujeto(s) políticos, un "nosotros" que hay que proteger ejerciendo violencia sobre un "ellos" ${ }^{2}$. Asimismo, la violencia como autodefensa se despliega ante una "posible" amenaza. Entrando en el terreno del phantasma social, la amenaza es situada en cualquiera de aquellos sujetos que se caracterizan como potencialmente violentos, en contraposición a aquellos que son vistos como sujetos a defender, llegando, si es necesario, a la destrucción de "la violencia encarnada".

Pero las posiciones no violentas son mayoritariamente calificadas como individualistas, como posiciones éticas que no tienen en cuenta la realidad social y la violencia padecida. Esto se debe, de acuerdo con Butler, al phantasma social heteronormativo, edadista y capacitista desde el que se piensan los sujetos políticos, y que tiene su representación más clara en los mitos del Estado de naturaleza. Lo que estos mitos, en la mayoría de sus formulaciones, ponen de relieve, es la posición de amo a partir de la cual el hombre blanco occidental actúa: la posición del hombre adulto, autónomo, independiente, que no necesita curas, que se abastece y sobrevive por sí solo en contraposición a los demás sujetos, considerados como esclavos de su dependencia (mujeres, niños, sujetos colonizados etc.). Esta fantasía, presente de manera inconsciente en el hacer político, muestra la ilusión de la vida que se vale por

\footnotetext{
${ }^{2}$ Véase Dorlin, 2019.
} 
sí misma, una vida que puede emanciparse mediante la razón y defenderse mediante la fuerza.

Contra esta caracterización, una política desde la no violencia parte de un imaginario antagónico: Butler afirma una vez más lo que atraviesa toda su obra y de donde la no violencia saca toda su fuerza: la profunda e íntima interdependencia de la vida. Desde su inicio, lo que caracteriza la vida humana es un "ser dado al otro", un estar en manos del otro; cuando un bebé nace, su vida recae, de la manera más clara, en las manos de los otros. Esta condición de radical interdependencia establece la verdadera igualdad de la vida humana: todos estamos, en la misma medida, abocados hacia los otros, conectados interdependientemente. Aceptar esta condición es afirmar una práctica no violenta, afirmar que todas las vidas son iguales, que toda vida merece ser llorada.

Sin embargo, esta condición pone de relieve el potencial destructivo de toda relación. Recogiendo la experiencia psicoanalítica de Klein y Freud, Butler afirma que las pasiones que atraviesan y constituyen la vida política son en ellas mismas ambivalentes: como el niño que teoriza Klein, amamos a quien nos cuida, y, a su vez, le odiamos por encarnar nuestra profunda interdependencia. Las pasiones que nos unen en la vida con los otros tienen también el poder de destruirla: del amor a la agresividad, del cuidado a la indiferencia.

En el último capítulo, Butler analiza la pulsión de muerte como aquello que amenaza la pervivencia de los lazos sociales a partir de los textos de Sigmund Freud. Es en "Duelo y melancolía" (Freud, 1993) que Freud caracteriza la melancolía como la vehiculación de la pulsión de muerte contra el yo a partir de la imposibilidad de aceptar la pérdida de un objeto amado, Ilegando a reclamar la propia vida para suturar la pérdida. A ella le opone la "manía", que busca romper el lazo con el objeto perdido, protestar contra la brutalidad del super-ego y sobrevivir a la pérdida del objeto amado. Es en esta "manía" que Butler divisa la fuerza necesaria para llegar a un saber hacer con la agresividad del super-ego, correlato en el sujeto de la autoridad en la sociedad; una posición subjetiva que no sucumba al círculo vicioso de las agresivas demandas del super-ego cultural, que busque preservar los lazos sociales que nos unen.

Pero esta preservación de la vida y de los lazos sociales no tiene que estar fundamentada en el amor o en una supuesta comunidad, sino en la afirmación de la vida interdependiente, de los lazos que nos unen y de los que nuestra vida pende. En las últimas líneas del texto, Butler (2020: 205) escribe:

We do not have to love one another to engage in meaningful solidarity. [...] We can always fall apart, which is why we struggle to stay together. Only then do we stand a chance of persisting in a critical commons: when nonviolence becomes the desire for the other's desire to live, a way of saying, "You are grievable; the loss of you is intolerable; and I want you to live; I want you to want to live, so take my desire as your desire, for yours is already mine."

En definitiva, el planteamiento que traza Butler en esta obra es de una gran potencia: contra la legitimación de la violencia instrumental, solo la afirmación del para con el otro, solo la práctica no violenta militante y agresiva es capaz de sostener 
el deseo de vivir; el deseo de vivir una vida que merezca la pena ser vivida, una vida que pueda ser llorada. Es de aquí, de nuestra radical interdependencia, de donde surge la fuerza de la no violencia.

\section{BIBLIOGRAFÍA}

Agamben, G. (2005). Homo sacer. Il potere sovrano e la nuda vita. Torino: Einaudi Editore.

Benjamin, W. (2010). "La tarea del traductor". En W. Benjamin. (2010) Obras Completas, IV, 1. Madrid: Abada.

- (1998). Para una crítica de la violencia y otros ensayos. Madrid: Taurus.

- (1998). "Sobre el lenguaje en general y sobre el lenguaje de los humanos". En W. Benjamin. (1998) Para una crítica de la violencia y otros ensayos. Madrid: Taurus.

Butler, J. (2020). The Force of Nonviolence. Londres: Verso Books.

- (2019). Marcs de Guerra: Quines vides plorem? Barcelona, Angle Editorial.

- (2010). Violència d'Estat, guerra i resistència. Barcelona: CCCB.

- (2009). Frames of War: When is Life Grievable? Londres: Verso Books.

— (2008). Vulnerabilitat, supervivència. Barcelona: CCCB.

- (2004). Precarious Life: The Power of Mourning and Violence. London: Verso Books.

Derrida, J. (1991). Force de loi. Le "fondement mystique de l'autorité". Paris: Éditions Galilée.

Dorlin, E. (2019). Autodefensa. Una filosofía de la violencia. Navarra: Txalaparta.

Freud, S. (1993). "Duelo y Melancolía". En S. Freud. (1993) Obras completas, XIV. Buenos Aires: Amorrortu.

Foucault, M. (2004). Naissance de la biopolitique. París: Gallimard.

Žižek, S. (2008). Violence. Londres: Profile Books LTD. 